\title{
Current and voltage noise in WO3 nanoparticle films.
}

Citation for published version (APA):

Hoel, A., Vandamme, L. K. J., Kish, L. B., \& Olsson, E. (2002). Current and voltage noise in WO3 nanoparticle films. Journal of Applied Physics, 91(8), 5221-5226. https://doi.org/10.1063/1.1423398

DOI:

10.1063/1.1423398

Document status and date:

Published: 01/01/2002

Document Version:

Publisher's PDF, also known as Version of Record (includes final page, issue and volume numbers)

Please check the document version of this publication:

- A submitted manuscript is the version of the article upon submission and before peer-review. There can be important differences between the submitted version and the official published version of record. People interested in the research are advised to contact the author for the final version of the publication, or visit the DOI to the publisher's website.

- The final author version and the galley proof are versions of the publication after peer review.

- The final published version features the final layout of the paper including the volume, issue and page numbers.

Link to publication

\section{General rights}

Copyright and moral rights for the publications made accessible in the public portal are retained by the authors and/or other copyright owners and it is a condition of accessing publications that users recognise and abide by the legal requirements associated with these rights.

- Users may download and print one copy of any publication from the public portal for the purpose of private study or research.

- You may not further distribute the material or use it for any profit-making activity or commercial gain

- You may freely distribute the URL identifying the publication in the public portal.

If the publication is distributed under the terms of Article $25 \mathrm{fa}$ of the Dutch Copyright Act, indicated by the "Taverne" license above, please follow below link for the End User Agreement:

www.tue.nl/taverne

Take down policy

If you believe that this document breaches copyright please contact us at:

openaccess@tue.nl

providing details and we will investigate your claim. 


\title{
Current and voltage noise in $\mathrm{WO}_{3}$ nanoparticle films
}

\author{
A. Hoel, ${ }^{a)}$ L. K. J. Vandamme, ${ }^{\text {b) }}$ L. B. Kish, ${ }^{\text {c) }}$ and E. Olsson \\ Department of Materials Science, The Angström Laboratory, Uppsala University, P.O. Box 534, \\ S-751 21 Uppsala, Sweden
}

(Received 21 February 2001; accepted for publication 8 October 2001)

\begin{abstract}
Current and voltage noise measurements have been carried out on nanoparticle $\mathrm{WO}_{3}$ films. The fluctuation dissipation theorem holds, which indicates that the observed noise is an equilibrium phenomenon. Results on the thinnest films show that noise measurements can be used for quality assessment of nanocrystalline insulating films. (C) 2002 American Institute of Physics.
\end{abstract}

[DOI: $10.1063 / 1.1423398]$

\section{INTRODUCTION}

Tungsten trioxide $\left(\mathrm{WO}_{3}\right)$ is a versatile material. It is widely used in different thin film technologies, for example as the electrochromic film in smart windows ${ }^{1}$ and as the active layer in chemical sensors. ${ }^{2}$

Temporal conduction fluctuations (noise) exist in all materials and the noise appears to have different characteristics depending on what mechanism is dominant in each case. Some common types of noise are thermal noise, shot noise, burst noise, $1 / f$ noise, and $1 / f^{2}$ noise. In earlier work it has been shown that noise can be a valuable instrument for analysis and for quality assessment of different electronic devices. ${ }^{3}$ In this article, the current and voltage noise of $\mathrm{WO}_{3}$ nanoparticle films have been studied.

\section{SAMPLE PREPARATION AND DESCRIPTION}

The $\mathrm{WO}_{3}$ samples were fabricated using an advanced gas deposition unit (ULVAC/VMC, Japan). The classical technique of gas evaporation was introduced in $1976^{4}$ and has become a leading method for production of high-quality nanoparticles. ${ }^{5-7}$ In the original advanced gas deposition arrangement, the source metal is heated up beyond the melting point, in an ambient of inert gas, and the source metal evaporates. The metal vapor condenses in the ambient gas and growth of ultrafine particles takes place. To obtain $\mathrm{WO}_{3}$ nanoparticle films, we modified the arrangement and used a reactive ambient gas, which in this case was synthetic air. ${ }^{8-10}$ The surface of the $\mathrm{W}$ pellet oxidizes and then the oxide sublimes. The vapor condenses and particles are formed as in the original arrangement. The particles are grown in the lower chamber and due to a pressure difference transported up, by a transfer pipe, into the deposition chamber, which is connected to a vacuum pump. The primary particles in the

\footnotetext{
a) Author to whom correspondence should be addressed; electronic mail: anders.hoel@angstrom.uu.se

b) Also with: Department of Electrical Engineering E H 5.15, Technische Universiteit Eindhoven, The Netherlands.

${ }^{c)}$ Formerly L. B. Kiss.
}

heated transfer pipe have a narrow size distribution, ${ }^{11}$ and they consist of single crystals. The primary particles were of a lognormal size distribution and the primary particle average size was around $5 \mathrm{~nm} \cdot{ }^{9}{ }^{, 10}$ Figure 1 illustrates the experimental setup for particle and film fabrication. The particles were deposited onto indium-tin-oxide (ITO) coated glass substrates.

The substrates were mounted on a computer controlled $x, y, z$ table which allowed various patterns to be made. Two different linear speed settings of the $x, y, z$ table were used, denoted by speed I and II. Speed II was twice that of speed I, which implies a ratio of two in the deposited number of particles/length. However, for the lower speed the heat in the deposited particles produced an extra sintering of the nanoparticles on the substrate. This meant that the thickness ratio of the films was less than a factor of 2 and the samples produced at a lower speed were more dense than the samples produced at a higher speed. ${ }^{9}$

In order to characterize the conduction noise and the dielectric properties of the samples, contacts of aluminum were evaporated onto the surface of the $\mathrm{WO}_{3}$ and onto the ITO surface. The diameter of the evaporated contacts was 1 $\mathrm{mm}$. The thickness $t_{c}$ of the $\mathrm{Al}$ contacts was about $1.5 \mu \mathrm{m}$, which was thick enough to avoid scratching by the probes. The film thickness $t$ was measured with a WYKO NT-2000 interferometer and ranged between $100 \mathrm{~nm}$ and $4 \mu \mathrm{m}$. A schematic picture of the sample arrangement is shown in Fig. 2.

\section{EXPERIMENTAL SETUP FOR THE NOISE MEASUREMENTS}

The noise in thin disk-shaped $\mathrm{WO}_{3}$ samples was measured using a probe station. In one setup we used a low noise voltage amplifier or current amplifier (Brookdeal 5004, Brookdeal 5002, or Stanford SR570 low noise current preamplifier) followed by a Hewlett Packard 35665A dynamic signal analyzer. In the second setup we used a cross correlation of two low noise voltage amplifiers (Brookdeal 5004) with the inputs in parallel, followed by a double channel 


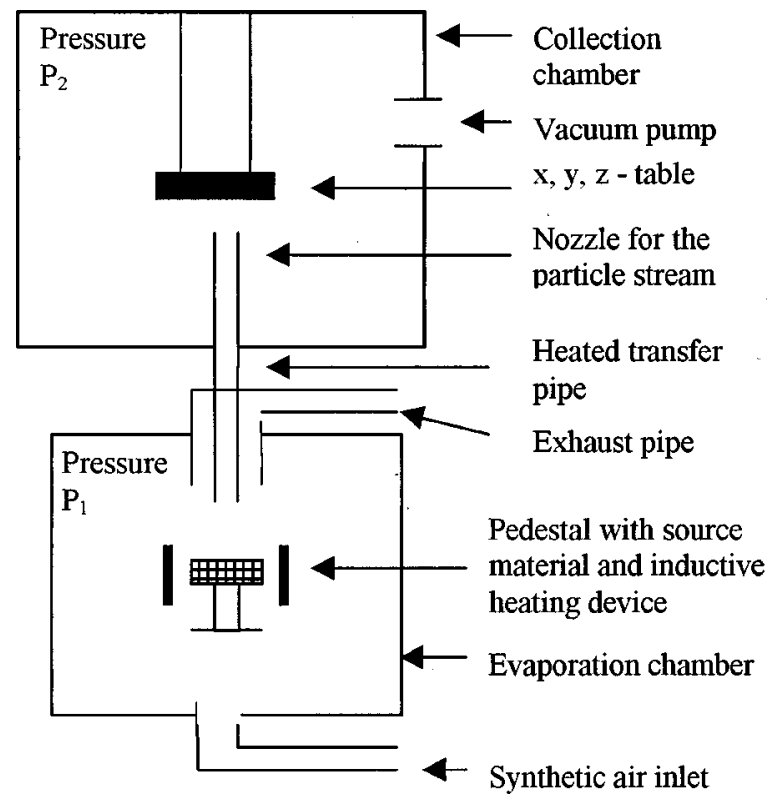

FIG. 1. Schematic picture of the gas-evaporation equipment. The pressure $P_{2}<P_{1}$ results in a flow of gas carrying the formed nanoparticles from the evaporation chamber into the deposition chamber.

Advantest R921E digital spectrum analyzer. The voltage and the current noise spectra have been investigated in the range from $1 \mathrm{~Hz}$ up to $100 \mathrm{kHz}$.

Dielectric measurements were carried out with a Hewlett Packard 4274A multifrequency LCR meter $(100 \mathrm{~Hz}-100$ $\mathrm{kHz})$.

\section{RESULTS}

The thermal voltage noise and current noise $S_{V}$ and $S_{I}$, respectively, of an unbiased sample (see the equivalent circuit in Fig. 3) in thermal equilibrium are described by the following relations:

$$
\begin{aligned}
S_{V} & =4 k T \operatorname{Re}[Z]=4 k T \frac{R}{1+(2 \pi f R C)^{2}} \\
& =4 k T \frac{\frac{1}{2 \pi f C^{\prime \prime}}}{1+\left(\frac{C^{\prime}}{C^{\prime \prime}}\right)^{2}},
\end{aligned}
$$

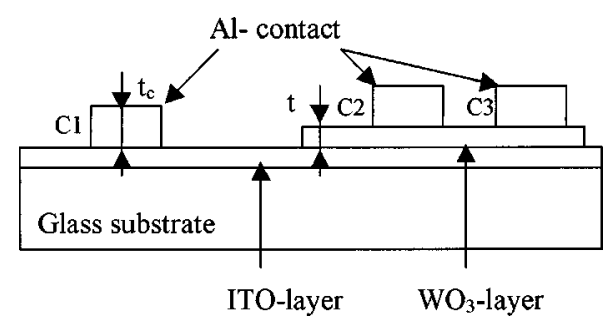

FIG. 2. Schematic view of the sample structure. The arrangement shows an $\mathrm{Al}$ contact evaporated onto ITO (denoted $C 1$ ) and two $\mathrm{Al}$ contacts on $\mathrm{WO}_{3}$ (denoted $C 2$ or $C 3$ ). The thickness of the dielectrica is $0.1 \mu \mathrm{m}<t<4 \mu \mathrm{m}$ and of the aluminum contact $t_{c}=1.5 \mu \mathrm{m}$. The probes were placed on either $C 2$ and $C 3$ or $C 1$ and $C 3$.
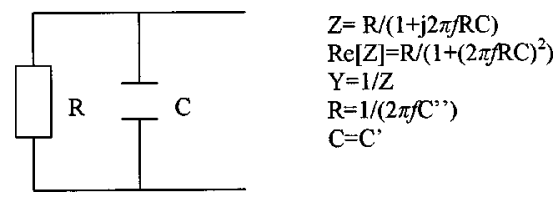

FIG. 3. An equivalent circuit representation of the samples where $R$ and $C$ are frequency dependent with $R=1 / 2 \pi f C^{\prime \prime}$ and $C=C^{\prime}$.

$$
S_{I}=4 k T \operatorname{Re}[Y]=4 k T \frac{1}{R}=4 k T^{*} 2 \pi C^{\prime \prime},
$$

where $k$ is Boltzmann's constant, $T$ the temperature in Kelvin, $Z$ the impedance, $Y$ the admittance, $f$ the frequency, $R$ the resistive part, and $C$ the capacitive part of the parallel representation of the impedance as shown in Fig. 3. Both parts can be frequency dependent. In Figs. 4-8 the calculated noise using Eqs. (1) and (2) is represented by full lines with values obtained from impedance spectroscopy in the frequency interval $100 \mathrm{~Hz}-100 \mathrm{kHz}$.

The $1 / f$ voltage noise $S_{V, 1 / f}$, caused by conductance fluctuations in a resistive sample with homogeneous current density exposed to a constant current is described by the empirical relation ${ }^{4,12}$

$$
S_{V, 1 / f}=\frac{V^{2} \alpha}{f N},
$$

where $V$ is the average voltage drop across the sample, $N$ the number of free carriers in the system, $f$ the frequency, and $\alpha$ a $1 / f$ noise parameter in the range $10^{-6}<\alpha<10^{-3}$ for good quality homogeneous samples. Figures $4-7$ present the experimental results from ac impedance measurements and noise measurements from samples with different thicknesses. The figures show the experimentally observed thermal noise of unbiased samples compared to the calculated noise using Eqs. (1) and (2) with experimental results from dielectric measurements. Measurements were carried out both on double $\mathrm{WO}_{3}$ layers (two layers in series) between contacts $C 2$ and $C 3$, and on single $\mathrm{WO}_{3}$ layers between contacts $C 1$ and $C 2$ according to Fig. 2. The expected relation between single and double $\mathrm{WO}_{3}$ layers was always observed; the resistance increased and the capacitance decreased by a factor of 2. This indicates that there was no contribution to the noise from the contacts.

In Fig. 5 the voltage noise from samples with a thickness of around $130 \mathrm{~nm}$ is shown. Note the plateau-like shape below $10 \mathrm{kHz}$ for unbiased samples. The plateau can be explained by shunting resistors of needle-like channels of aluminum penetrating the porous structure of the $\mathrm{WO}_{3}$. As the aluminum is evaporated, the widest pores are immediately filled with aluminum and channels are formed along the cross section of the thin $\mathrm{WO}_{3}$ layer. This results in a frequency independent resistance with a value roughly given by $R=\rho_{\mathrm{Al}} l / \pi a^{2}$, where $\rho_{\mathrm{Al}} \approx 10^{-5} \Omega \mathrm{cm}$ in the narrow chan- 


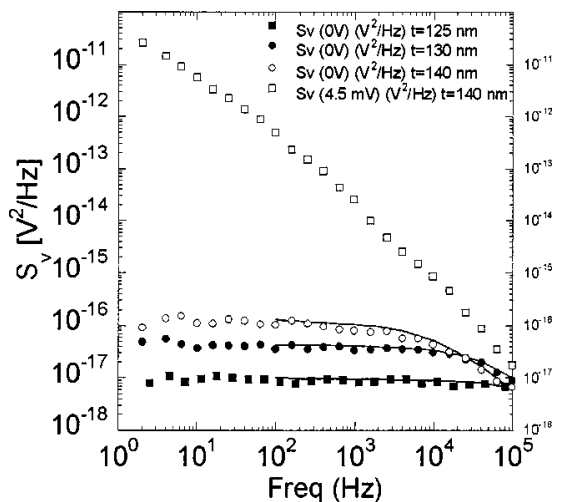

FIG. 4. The spectral noise for three different samples with a thickness of about $130 \mathrm{~nm}$. The samples are presented in order of increased thickness; $(\boldsymbol{\square}),(\bullet)$, and $(\bigcirc)$. The graph also shows the noise of the thickest sample when biased with $4.5 \mathrm{mV}(\square)$. The voltage noise follows a $1 / f$ dependence and is due to the $1 / f$ noise in penetrating channels of aluminum in the structure of nanoparticles. The corner frequency of the spectra of unbiased samples is for the thinnest sample around $100 \mathrm{kHz}$, but for the slightly thicker samples the corner frequency is about $20 \mathrm{kHz}$. The full lines are calculated from $4 k T \operatorname{Re}[Z]$

nels (slightly higher than for bulk material due to additional surface scattering) and $l$ is the length of the aluminum channel penetrating the porous dielectric and $2 a$ the diameter of the channel. Choosing the smallest possible value for $l$ which is the thickness of the dielectric layer (sample thickness), i.e., $130 \mathrm{~nm}$, and choosing $2 a \approx 2 \mathrm{~nm}$, the assumed cavity diameter between the nanoparticles of size order of $5 \mathrm{~nm}$, we calculate $R \approx 4.2 \mathrm{k} \Omega$. Similar experimental results have been observed in Refs. 9 and 11. This calculated resistance is in agreement with the observed impedance and corresponds to a voltage noise level of $6 \times 10^{-17} \mathrm{~V}^{2} / \mathrm{Hz}$, which is in the same order of magnitude as the value observed from the noise measurements. The criterion for observing $1 / f$ noise above the thermal noise for a homogeneous conductor is given by $S_{V, 1 / f}>S_{V, \text { th }}$. With Eqs. (1) and (3) and for $1 / N$ $=q \mu R / l^{2}$ with $l$ the distance between the electrodes, $q$ the charge, and $\mu$ the mobility of the free carriers this inequality becomes

$$
\frac{V^{2} \alpha}{f N}>4 k T R
$$

or

$$
\frac{E^{2} \alpha q \mu}{f}>4 k T
$$

For materials with very low $\mu$, such as disordered dielectric, hopping types of mobilities ( $\mu \ll 1 \mathrm{~cm}^{2} / \mathrm{V}$ s) occur. If we assume $f \approx 1 \mathrm{kHz}$ and $T=300 \mathrm{~K}$ and $\alpha=10^{-4}$, the necessary field strength $E$ to observe $1 / f$ noise often becomes stronger than the breakdown field strength of the material. This ex-
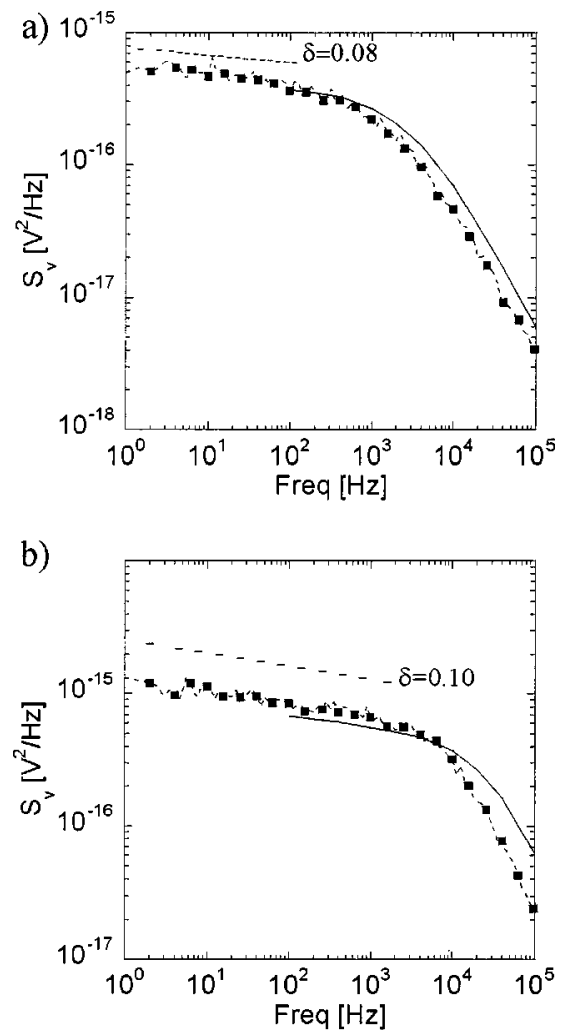

FIG. 5. The $S_{V}$ of high quality samples with a thickness of $145 \mathrm{~nm}$ (a) and $4.0 \mu \mathrm{m}(\mathrm{b})$, respectively. Note the slope below the corner frequency: for (a) the slope is $\delta=0.08$ and for (b) the slope is $\delta=0.10$. There is a systematic small mismatch between the noise measurements and calculated values stemming from dielectric measurements. The ultralow noise preamplifier has an additional parasitic capacitance at the input of about $50 \mathrm{pF}$ and the noise data are not corrected for that.

plains why the $1 / f$ noise is not often observed above the thermal noise in dielectrics. Nevertheless, a sample can reveal a defect due to aluminum electrodes penetrating into and through the thin dielectric. Aluminum channels penetrating silicon integrated circuits were observed as early as

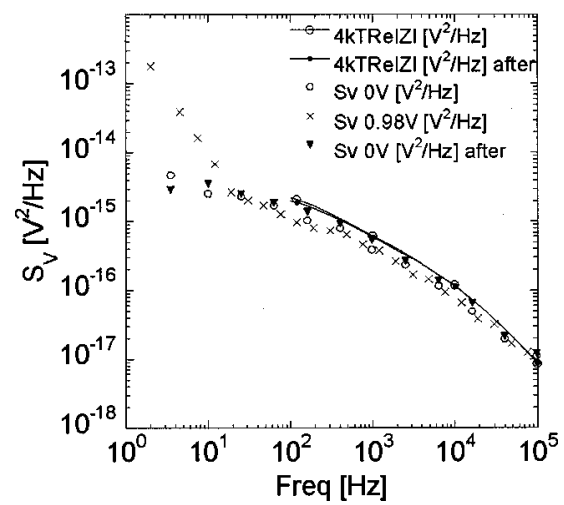

FIG. 6. A sample of thickness $t=160 \mathrm{~nm}$. The full lines correspond to calculated noise obtained from ac measurements before $(\bigcirc)$ and after $(\boldsymbol{O}$ biasing $(100 \mathrm{~Hz}-100 \mathrm{kHz})$. The symbols $(\bigcirc)$ correspond to unbiased, $(\times)$ to biased, and $(\boldsymbol{\nabla})$ to unbiased condition after biasing. The sample is biased up to $0.98 \mathrm{~V}(\mathrm{X})$ and there is only a small deviation between the measured noise and the calculated noise (the range $1-10^{5} \mathrm{~Hz}$ and $100-10^{5} \mathrm{~Hz}$ ). There is no change in noise after biasing and therefore no degradation of the sample. 

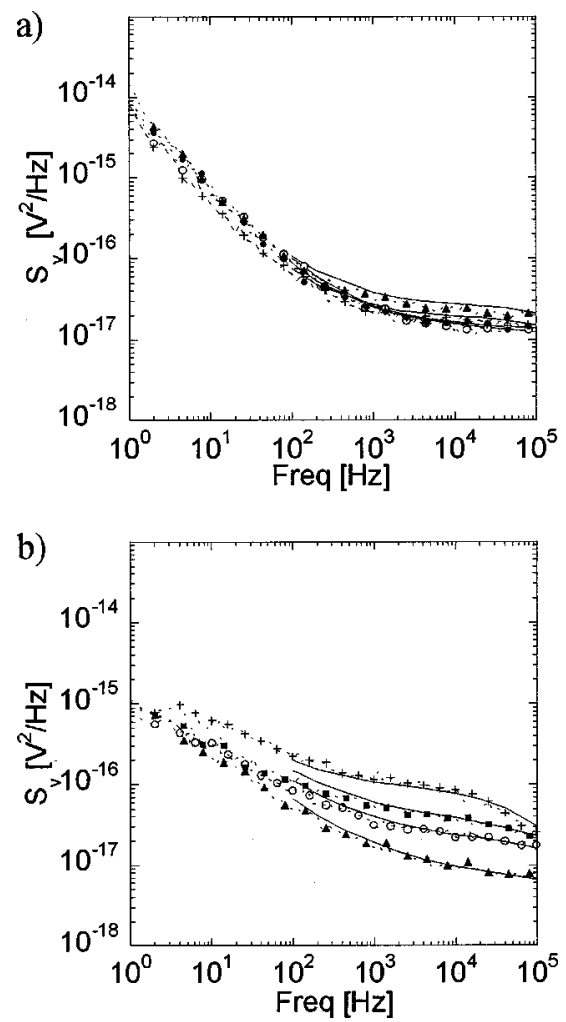

FIG. 7. (a) The noise of a set of samples produced at speed I. (b) The noise of a set of samples produced at speed II. Note the difference in the spread of noise due to a more or less dense film. The films have a thickness of: (a) 600 $\mathrm{nm}$ and (b) $1.0 \mu \mathrm{m}$.

1973. ${ }^{13}$ Figure 5 shows the noise from unbiased and biased samples. At a dc voltage of $4.5 \mathrm{mV}$ a $1 / f$ noise due to resistance fluctuations is observed. This is not due to fluctuations in the dielectric, but to fluctuations in the resistance of the aluminum channels penetrating through the dielectric. The calculated noise for unbiased samples using $S_{V}=4 k T \operatorname{Re}[Z]$ with $Z$ from ac measurements ( $100 \mathrm{kHz}$ down to $100 \mathrm{~Hz}$ ) are shown in the graph (full line) and there is good agreement with the measured noise. There is an expected characteristic $1 / f$ noise for the biased sample given by Eq. (3). After biasing, the noise was measured again. No change was observed, which means that the aluminum channels did not degrade due to the bias conditions. Having the porous structure in mind and calculating the $S_{1 / f}$ for a thin aluminum channel that penetrates the film results in a $1 / f$ noise well above thermal noise because now the mobility $\mu \gg 1 \mathrm{~cm}^{2} / \mathrm{V} \mathrm{s}$ [see Eq. (5)]. This is in agreement with experimental spectra for the biased sample. For the different samples a decrease in corner frequency is observed for an increase in thickness. This is due to the fact that resistance does not scale with thickness because the thicker the sample the higher the chance of having a constriction somewhere in the aluminum channel. Thicker films are more sintered and dense, hence the aluminum channels have a smaller cross section. If we consider the aluminum channels as a homogeneous resistor, a value for the $1 / f$ noise parameter $\alpha$ can be calculated from the $1 / f$ noise from a biased sample and the relation $\left(f S_{V} / V^{2}\right) l^{2} / q \mu R=\alpha . \quad$ For $\quad \mu=100 \mathrm{~cm}^{2} / \mathrm{V} \mathrm{s}, \quad S_{V}=5$ $\times 10^{-11} \mathrm{~V}^{2} / \mathrm{Hz}$ at $f=1 \mathrm{~Hz}$ with a bias $V=4.5 \mathrm{mV}$ and $R=6 \mathrm{k} \Omega$. This implies a value of $\alpha=5 \times 10^{-3}$, which is in agreement with $\alpha$ values for metals in general. ${ }^{14,15} \alpha$ values well above $2 \times 10^{-3}$ indicate a current crowding problem on a microscopic scale in narrow necks in a conducting path. Such high $\alpha$ values are apparent high values and are discussed in an earlier work by Vandamme and Vandamme. ${ }^{16}$

The thicker films show a higher density compared to the thinner films. The particles are more sintered on the substrate due to the internal heat of the particles. Hence, the thickest films are without aluminum channels. In Figs. 6(a) and 6(b) the thermal noise is shown for two samples without aluminum channels with thicknesses of $145 \mathrm{~nm}$ (fabricated at speed II) and $4.0 \mu \mathrm{m}$ (fabricated at speed I), respectively. The difference in density gives rise to a difference in the corner frequency, which appears for the sample in Fig. 6(a) at $\sim 1.5 \mathrm{kHz}$ and in Fig. 6(b) at $\sim 15 \mathrm{kHz}$. This trend can be explained as follows: the thinner the sample, the less dense the material, the higher the resistivity $\rho$ and the smaller the relative permittivity $\epsilon_{r}$. The $R C$ time constant in homogeneous materials is nothing other than the dielectric time constant given by $R C=\tau_{d}=\rho \epsilon_{0} \epsilon_{r}$. From these two opposite trends for the variation of $\rho$ and $\epsilon_{r}$ with density, $\rho$ versus density plays the dominant role. From the thermal noise at 1 Hz we observe a ratio $R_{\text {thinn }} / R_{\text {thick }} \approx 1 / 3$ and a thickness ratio of $27(4 / 0.145)$ which means $\rho_{\text {thinn }} / \rho_{\text {thick }} \approx 9$. This means that $\epsilon_{r}$ is not a strong function of thickness and the factor of 10 shift in the observed corner frequency can be explained mainly by a factor of 10 in $\rho$. The slope below the corner frequency, denoted by $\delta$, is in strong contrast to the plateaulike shape observed for the thinnest samples shown in Fig. 5 with $\delta=0$ (unbiased samples). $S_{V}$ is proportional to $f^{\delta}$. In Fig. 6(a) the slope is $\delta=0.08$ and in Fig. 6(b) the slope is $\delta=0.10$. The noise level is about 1 decade higher than for the thinnest samples shown in Fig. 5 caused by the absence of shunting aluminum channel resistors.

In Fig. 6 the thermal voltage noise of a sample of thickness of $160 \mathrm{~nm}$ is presented. The noise is measured in a sequence of unbiased, biased, and again unbiased. The sample is biased up to $0.98 \mathrm{~V}$ and there is no change in the noise. The deviation in the low frequency range is probably due to drift. The sample remains unchanged after biasing. Again the measured noise is compared to the calculated noise (full lines) obtained from dielectric measurements.

In Fig. 7 the voltage noise of two sets of samples are shown, where the samples in Fig. 7(a) have a thickness of $600 \mathrm{~nm}$ fabricated at speed I and the sample in Fig. 7(b) has a thickness of $1.0 \mu \mathrm{m}$ fabricated at speed II. The samples fabricated at speed II have a more porous structure and therefore a larger spread in dielectric properties and noise than the samples fabricated at speed I. This is shown as a difference in the scattering of the results in Figs. 7(a) and 7(b).

From two independent unbiased noise measurements: $S_{V}(f)$ with a low noise voltage amplifier and $S_{I}(f)$ with a low noise current amplifier, the $S_{V *} S_{I} /(4 k T)^{2}$ values were calculated. This outcome is compared with calculated results from dielectric measurements. The following relation is used and derived from Eqs. (1) and (2) 

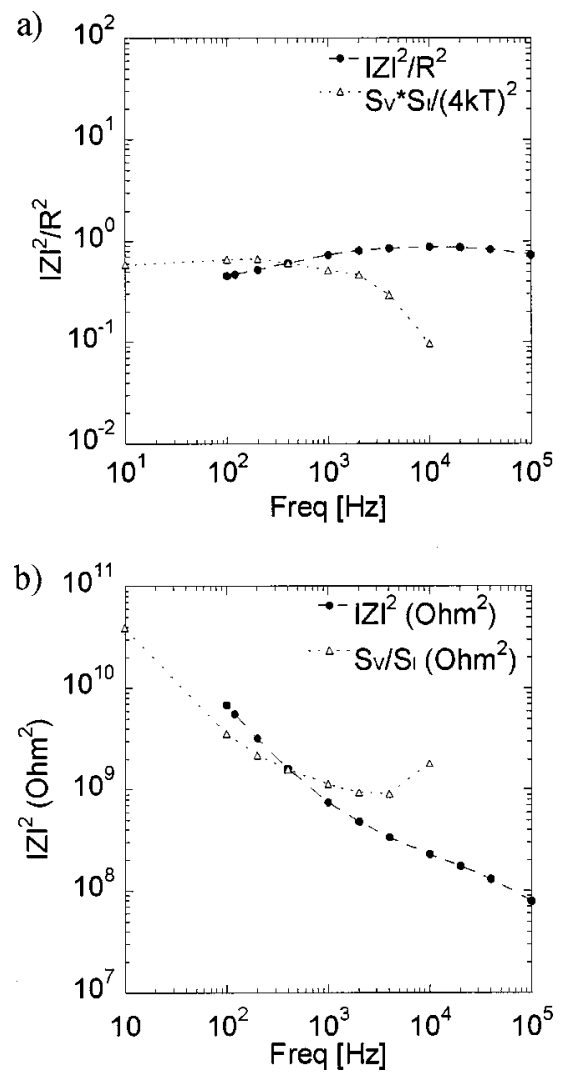

FIG. 8. (a) The comparison of $S_{v}{ }^{*} S_{I} /(4 k T)^{2}$ calculated from the thermal noise and $|Z|^{2} / R^{2}$ calculated from the impedance measurements [see Eq. (6)]. (b) The comparison of $S_{v} / S_{I}$ calculated from thermal noise and $|Z|^{2}$ calculated from the impedance measurements [see Eq. (7)]. Apart from some band limiting problems with the current amplifiers above $3 \mathrm{kHz}$ there is good agreement.

$$
\frac{S_{V^{*}} * S_{I}}{(4 k T)^{2}}=\frac{1}{1+(R 2 \pi f C)^{2}}=\frac{1}{1+\left(\frac{C^{\prime}}{C^{\prime \prime}}\right)^{2}}=\frac{\left|Z^{2}\right|}{R^{2}} .
$$

On the other hand, the ratio $S_{V} / S_{I}$ calculated from experimentally observed noise results must agree with the outcome of the impedance measurements using Eq. (7) below, which is based on Eqs. (1) and (2).

$$
\frac{S_{V}}{S_{I}}=\frac{R^{2}}{1+(R 2 \pi f C)^{2}}=\frac{\frac{1}{\left(2 \pi f C^{\prime \prime}\right)^{2}}}{1+\left(\frac{C^{\prime}}{C^{\prime \prime}}\right)^{2}}=|Z|^{2}
$$

The experimentally observed $S_{V *} S_{I}$ and the calculated values from Eq. (6) are shown in Fig. 8(a). The $S_{V} / S_{I}$ values and the calculated values from Eq. (7) are shown in Fig. 8(b). The sample thickness is $400 \mathrm{~nm}$. There is good agreement between the noise measurements and calculated data obtained from impedance spectroscopy measurements in the interval $10^{2}-10^{3} \mathrm{~Hz}$. At higher frequencies the influence of the cutoff frequency for the low noise current amplifiers used for $S_{I}$ measurements is dominant and therefore the noise results diverge from the calculated ones, which are obtained from the impedance spectroscopy.

\section{CONCLUSION}

There is good agreement between the thermal voltage noise and the values calculated from impedance measurements using $4 k T \operatorname{Re}[Z]$ or $4 k T \operatorname{Re}[Y]$. Hence the fluctuation dissipation theorem is valid for this type of dielectric material. The measured noise is an equilibrium phenomenon. ${ }^{17}$ For high quality samples there is no change in the noise level caused by an applied voltage of up to $1 \mathrm{~V}\left(6.2 \times 10^{4} \mathrm{~V} / \mathrm{cm}\right.$ field strength) and the sample remains undamaged after the biased condition. The $1 / f$ noise spectra in biased samples indicate fluctuations in the shunt resistance and can be used as a diagnostic tool for sample quality. The $1 / f$ noise results on the thinnest films, showing that noise measurements can be used for quality assessment of nanocrystalline insulating films. For unbiased conditions the thinnest and most porous samples exhibited a plateau-like shape over several decades in the noise as well as in the impedance versus frequency. This is due to aluminum channels originating from the aluminum contacts penetrating the dielectric layer and therefore suppressing the influence of the real part of the dielectric $\mathrm{WO}_{3}$ on the voltage noise. For thicker and more dense samples a proportionality in $S_{V}$ versus $f^{\delta}$ was observed with $0.05<\delta<0.20$, indicating a more genuine dielectric response.

\section{ACKNOWLEDGMENTS}

This work has been financially supported by COBRA (Inter-University Research Institute Communication Technology: Basic Research and Application) and by AME (Center for Advanced Micro Engineering, The Angström Laboratory at Uppsala University). The authors would like to thank Joost Briaire at Technische Universiteit Eindhoven, The Netherlands, for help with the experimental setup.

${ }^{1}$ C. G. Granqvist, Handbook of Inorganic Electrochromic Materials (Elsevier, Amsterdam, 1995).

${ }^{2}$ J. Tamaki, Z. Zhang, K. Fujimori, M. Akiyama, T. Harada, N. Miura, and N. Yamazoe, J. Electrochem. Soc. 141, 2207 (1994).

${ }^{3}$ L. K. J. Vandamme, IEEE Trans. Electron Devices 41, 2176 (1994).

${ }^{4}$ C. G. Granqvist and R. A. Buhrman, J. Appl. Phys. 47, 2200 (1976).

${ }^{5}$ C. Hayashi, R. Uyeda, and A. Tasaki, Ultra-Fine Particles (Noyes, Westwood, 1997).

${ }^{6}$ R. W. Siegel, Annu. Rev. Mater. Sci. 21, 559 (1991).

${ }^{7}$ H. Gleiter, Nanostruct. Mater. 1, 1 (1992).

${ }^{8}$ J. L. Solis, A. Hoel, L. B. Kish, and C. G. Grandquist, J. Am Ceram. Soc. 84, 1504 (2001).

${ }^{9}$ A. Hoel, L. B. Kish, R. Vajtai, G. A. Niklasson, C. G. Grandquist, and E. Olsson, Mater. Res. Soc. Symp. Proc. 581, 15 (2000). 
${ }^{10}$ A. Hoel, L. B. Kish, R. Vajtai, and E. Olsson, Proceedings of the 51st Annual Meeting Scandinavian Society Electron Microscopy, Bergen, Norway, 1999 , p. 51.

${ }^{11}$ J. Söderlund, L. B. Kiss, G. A. Niklasson, and C. G. Granqvist, Phys. Rev. Lett. 80, 2386 (1998).

${ }^{12}$ F. N. Hooge, T. G. M. Kleinpenning, and L. K. J. Vandamme, Rep. Prog. Phys. 44, 479 (1981).
${ }^{13}$ T. E. Price and L. A. Berthoud, Solid-State Electron. 16, 1303 (1973).

${ }^{14}$ F. N. Hooge, Phys. Lett. 29A, 139 (1969).

${ }^{15}$ D. M. Fleetwood, J. T. Masden, and N. Giordano, Phys. Rev. Lett. 50, 450 (1983).

${ }^{16}$ E. P. Vandamme and L. K. J. Vandamme, Microelectron. Reliab. 40, 1847 (2000).

${ }^{17}$ F. Green and M. P. Das, AIP Conf. Proc. 511, 422 (2000). 